\title{
Ectopic thyroid tissue in the adrenal gland: report of a case
}

Emre Bozkirli ${ }^{1}$, Okan Bakiner $^{1}$, Sedat Belli², Emrah Kocer ${ }^{3}$, Serife Ulusan $^{4}$, Mehmet Reyhan $^{5}$

${ }^{1}$ Baskent University, Faculty of Medicine, Endocrinology Department, Adana, Turkey

${ }^{2}$ Baskent University, Faculty of Medicine, General Surgery Department, Adana, Turkey

${ }^{3}$ Baskent University, Faculty of Medicine, Pathology Department, Adana, Turkey

${ }^{4}$ Baskent University, Faculty of Medicine, Radiology Department, Adana, Turkey

${ }^{5}$ Baskent University, Faculty of Medicine, Nuclear Medicine Department, Adana, Turkey

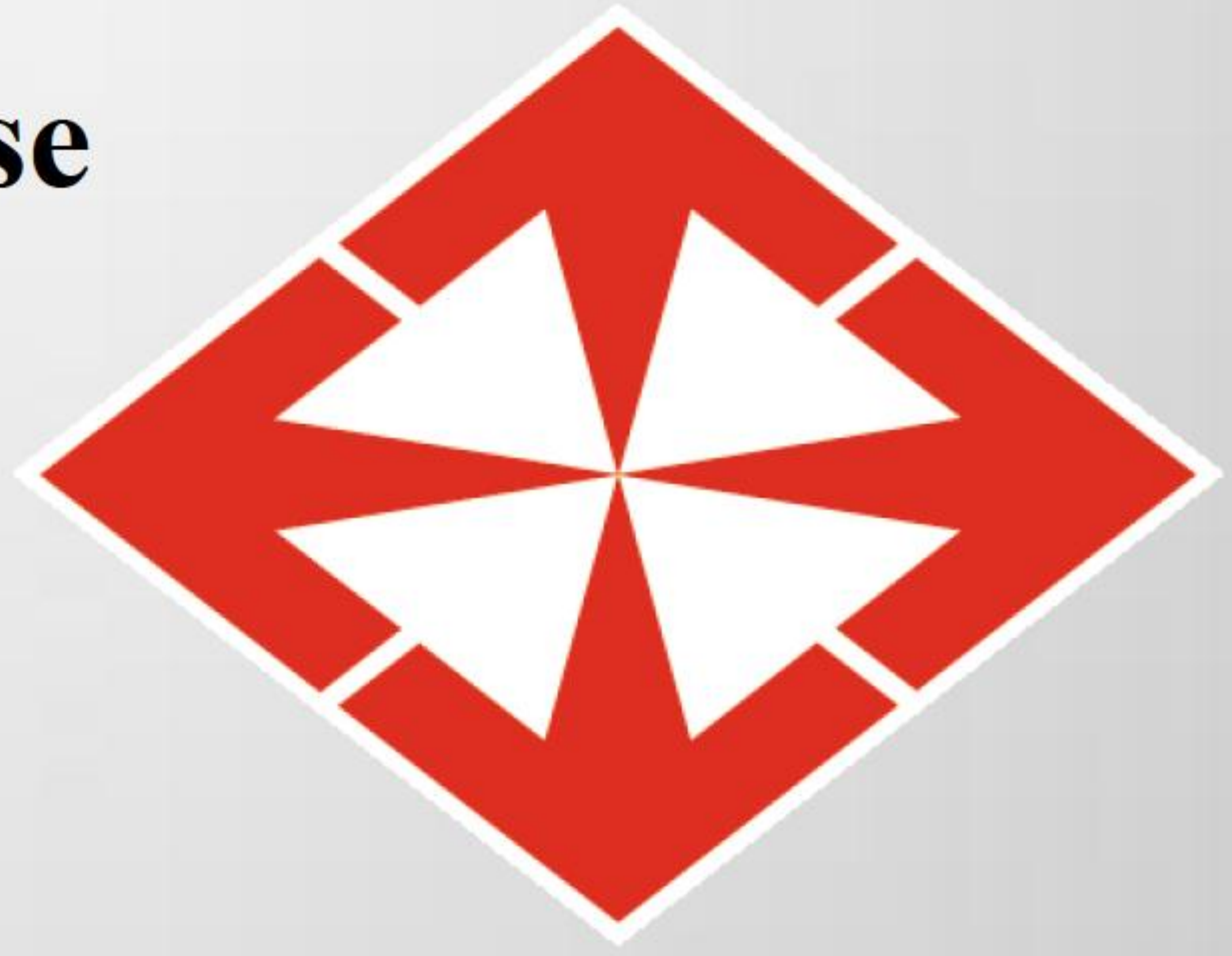

Background: Ectopic thyroid tissue (ETT) can be explained as the localisation of thyroid parenchyma outside the orthotopic position of the thyroid gland. It can be more easily found in the tongue, neck, mediastinum, great vessels, heart and anywhere along Wölfler area, but presentation in the adrenal glands is absolutely very rare (1-2).

Case: A 39-year-old woman was referred to our Endocrinology outpatient clinic with an incidental adrenal mass which was seen in abdomen CT performed because of a nonspecific abdominal pain. Her abdomen $\mathrm{CT}$ revealed a $13 \times 18 \mathrm{~mm}$ non-adenoma solid mass in the right adrenal gland which showed 43 Hounsfield units(HU) in precontrast series, $71 \mathrm{HU}$ in portal phase and $67 \mathrm{HU}$ in late phase(Figure1). Endocrinologic evaluation showed that it was a non-functional tumour. Her PET CT scan revealed a hypermetabolic nodular lesion in the right adrenal gland and physiological FDG uptake in bilateral adnexal regions. The patient underwent surgery and histological examination showed thyroid tissue in the adrenal gland seen as large islets (Figure 2). No sign of atypia was observed. Immunohistochemical studies were negative for CK-19, HBME-1 and GAL-3.Patient's thyroglobulin level was within normal ranges as $23.80 \mathrm{ng} / \mathrm{mL}(1.60-55)$.She had a subtotal thyroidectomy history and her current neck USG revealed several benign appearing thyroid nodules with the largest as $12 \times 9 \mathrm{~mm}$ in diameter. $A$ thyroid fine needle aspiration biopsy was performed and found as benign.

Conclusion: To date, intraadrenal ETT has been reported in 10 cases in the literature. Only one of them was solid like our case, and the remaining were cystic lesions. Clinicians and pathologists must be careful during distinguishing it from metastatic thyroid cancer. For our case we planned a complementary thyroidectomy to exclude a metastatic thyroid cancer. However her PET CT scan results, thyroglobulin level, benign appearance of thyroid nodules, benign biopsy result and absence of any other solid organ metastasis may propose an existence of ETT in the adrenal gland.

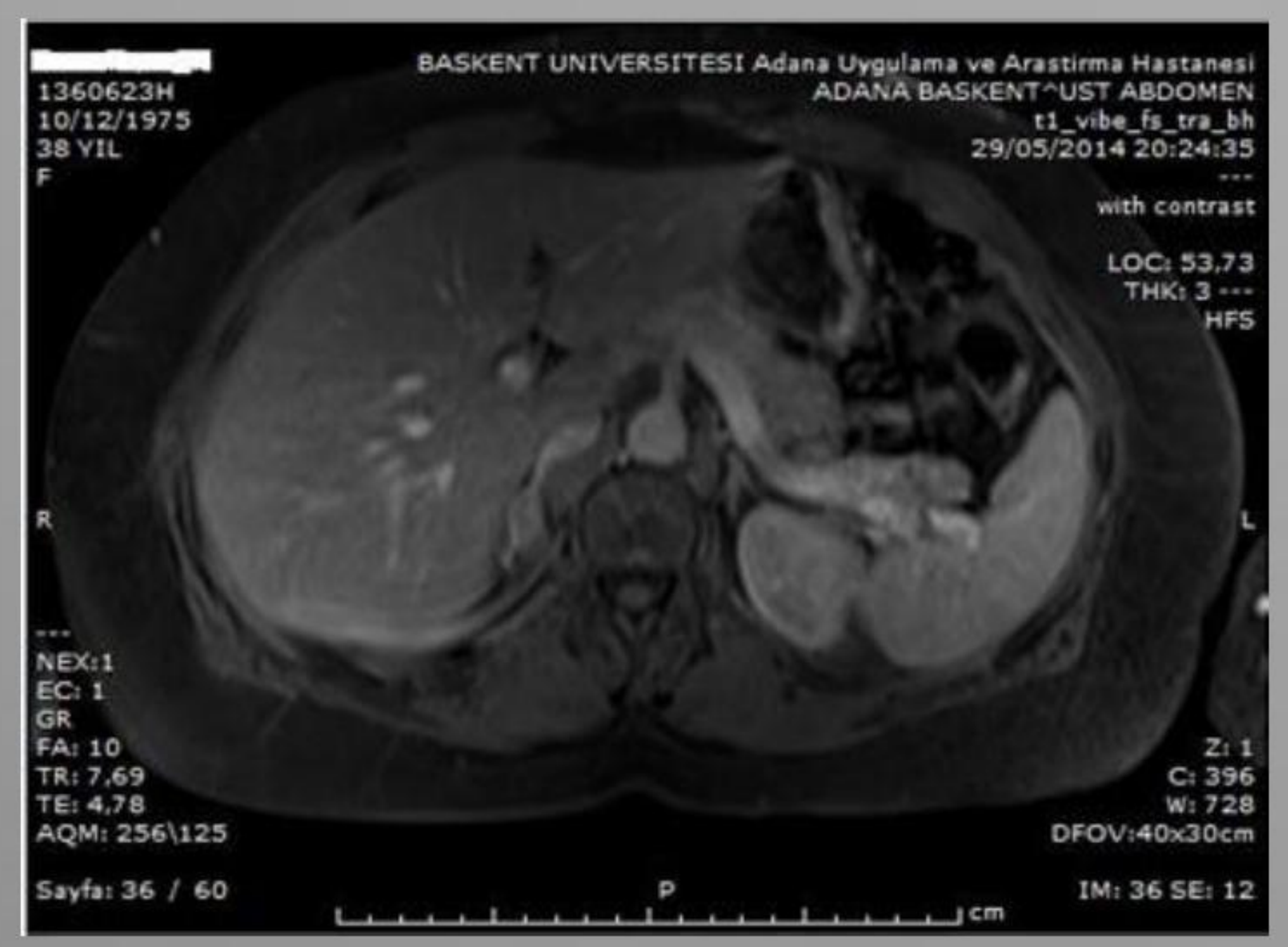

Figure 1: Non-adenoma solid mass in the right adrenal gland.

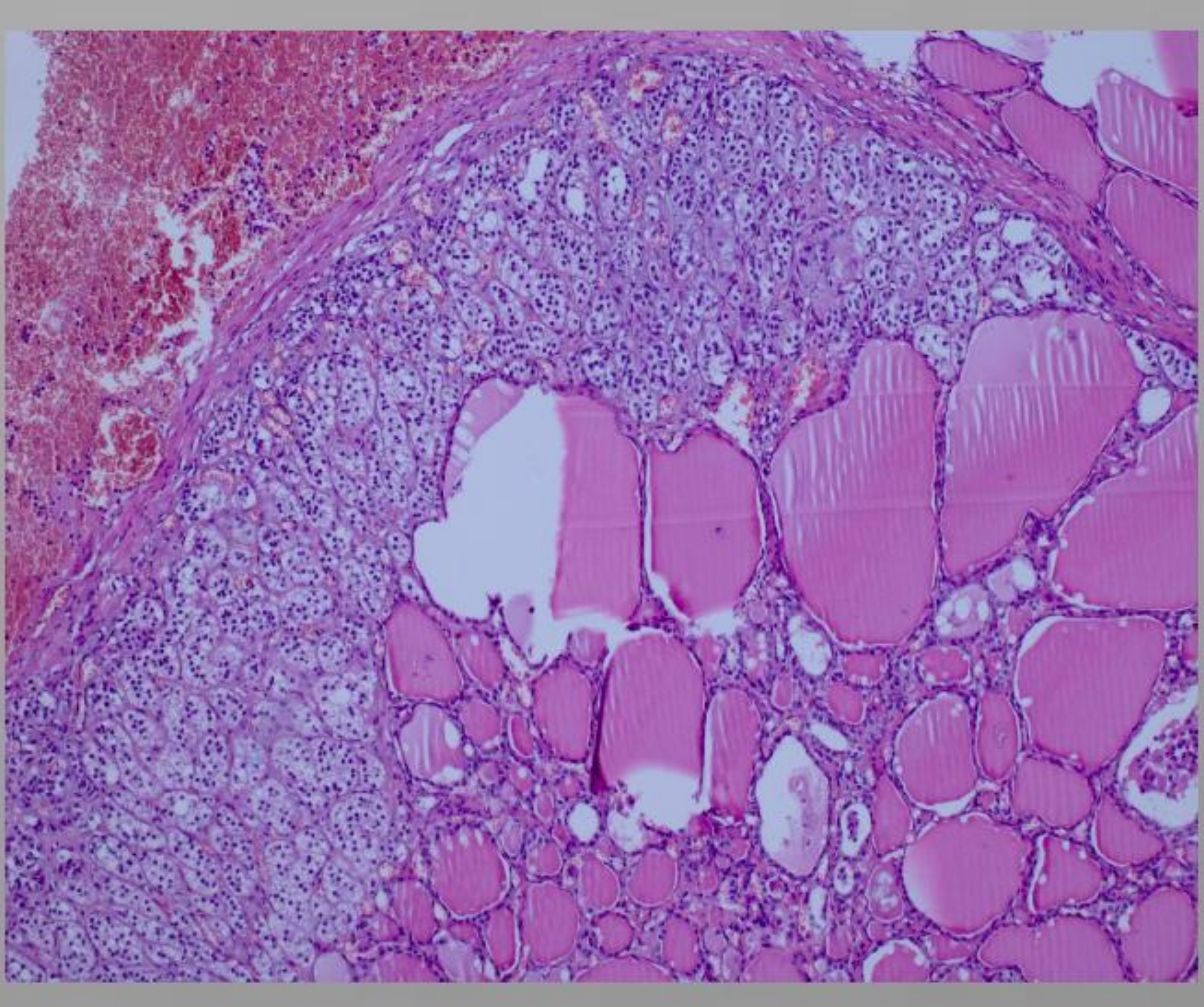

Figure 2: Thyroid tissue in the adrenal gland.

REFERENCES: 1. Gian Piero Casadei et al. Ectopic thyroid tissue in the adrenal gland. Int J Surg Pathol, DOI:10.1177/1066896914541001

2. Alfredo Romero-Rojas et al. Ectopic thyroid tissue in the adrenal gland: a report of two cases with pathogeneticimplications. Thyroid 2013;23(12):1644-1650. 